\title{
Change and Tensions in Non-profit Organizations: Beyond the Isomorphism Trajectory
}

\author{
Malin Arvidson ${ }^{1}$ (D)
}

Published online: 18 July 2018

(C) The Author(s) 2018

\begin{abstract}
Research on the relationship between non-profit organizations (NPOs) and the public sector has been dominated by predictions of isomorphism where change and tensions in NPOs are attributed an imposing institutional setting. This article argues that research represents a selective perspective on organizational life due to its portrayal of organizational change as synonymous with an isomorphic, linear trajectory. The purpose of this article is to illustrate different sources and characteristics of change and tension. The article presents an analytical framework comprising of four components: evolving change, episodic change, inherent dilemmas, and conflicting logics, facilitating an understanding of the organization as movement. The analysis of a case study organization suggests that by identifying different dimensions of changes and tensions we can gain a richer understanding of the complexity of processes underpinning the organization as movement. The analysis reveals how multiple, parallel processes related to change and tensions generate reflections that drive integrity and identity formation at individual and organizational levels.
\end{abstract}

Keywords Isomorphism - Change - Tensions · Organization as movement $\cdot$ Non-profit organizations

Malin Arvidson

Malin.arvidson@soch.lu.se

1 School of Social Work, Lund University, Box 23, 22100 Lund, Sweden

\section{Introduction}

For decades, scholars have been concerned that along with increased interdependence between non-profit organizations (NPOs) and the public sector, NPOs lose their ability to represent and address the needs of their client groups as they are becoming more like public sector organizations (Billis \& Glennerster 1998; Lipsky \& Smith 1989). Arguments maintain that new positions and expectations of NPOs lead to organizations jeopardizing their distinctive attributes that come from being community-based and user-led. In many countries, changes in the welfare state continue to be accompanied with invitations for NPOs to engage as service providers. Concepts such as marketization, outsourcing, competition, public-private partnership, new public management, and client choice can be used to describe some of the characteristics of welfare service regimes today. For NPOs operating close to the public sector, in contexts characterized by different institutional logics to that of non-profit, voluntary and communitybased organizations, changes to organizational characteristics of NPOs do not come as a result of conscious choice but rather as one of the unintended consequences (Hwang \& Powell 2009; Verbruggen et al. 2011). These events have set an agenda, across the world, for research on the implications of these developments for service-delivering NPOs: what happens to organizations when sectoral boundaries become blurred, fuzzy, and unclear (Brandsen et al. 2005)? And what happens to organizations when faced with conflicting institutional logics and demands under circumstances characterized by power differentials (Pache \& Santos 2010)?

Research on organizational change in this context has been dominated by new institutional theory, which argues that change is the result of organizations being influenced 
by surrounding institutions. In the case of NPOs, concepts such as adaptation and compliance are often used to describe organizational response to pressure towards mainstreaming according to dominating institutional logics. While this theoretical perspective is in many ways well suited to capture the reality of NPOs operating close to the public sector, the dominance of new institutional theory has led to the neglect of theoretical perspectives that advocate other ways of understanding organizational change. The article contributes to debates about how we can understand and conceptualize change in NPOs by presenting alternative theories of organizational change. Through an analytical framework that draws on insights offered by such theories, the study illustrates how we can gain a more complex and in-depth picture of how these organizations work.

New institutional theory and the concept of isomorphism have influenced research that seeks to define the source, process, and results of change related to NPOs in this context. An institutional environment that includes diverse organizational actors, but is dominated by a public sector welfare regime has, it is argued, 'constraining influences' (Verbruggen et al. 2011) on NPOs as it exercises isomorphic pressure towards 'homogeneity, in structure, culture and output' across organizations of different institutional origin (DiMaggio \& Powell 1983: 147). Although in principle isomorphism could involve the 'diffusion of good practices' (Leiter 2013), the term is primarily associated with a fear that NPOs will lose important organizational traits as they become more bureaucratic and/or more business-like (Buckingham 2012). Goals, preferred means of intervention, supervision, and control as defined by the public sector take precedence over organizational value bases and structures that come from alternative ways of defining and addressing social needs. Research points to how competition for resources, bidding procedures, and funding that comes with requirements regarding the scope and content of services all force NPOs to change in ways that pose threats to organizational mission (Bennett \& Savani 2012; Dolnicar et al. 2008; Eikenberry \& Kluver 2004; Hasenfeld \& Garrow 2012). New forms of collaboration that build on social investment aimed at the scaling up of successful non-profit-based operations require new organizational management with focus on output and efficiency rather than on fulfilling a mission to accomplish social outreach of services and specific aims to cater for the poorest of the poor, the hardto-reach and hard-to-engage (Copestake 2007).

The concepts of institutional pressure and isomorphism have significantly inspired studies on changes to NPOs, and they represent both a change trajectory outlined by external forces and the ensuing struggles related to the need for adaptation and organizational autonomy typical for many
NPOs. In other words, these concepts offer a theoretical frame for exploring the dilemmas and complexities that Lipsky \& Smith and Billis \& Glennerstedt identified some decades ago as expected consequences of an increased interdependence between the public sector and NPOs. Analyses that explore homogenization of NPOs refer to the power of the organization's institutional environment, and its preferred logics (Beckert 2010) and studies of change in NPOs continue to assume that institutions are 'defining the very conditions' of organizational structure and practice (Goodrick \& Salancik 1996: 26). While this makes for a compelling and often appropriate analytical framework to apply to NPOs that are increasingly integrated into the public sector, it is not without criticism. Recent studies of NPOs are influenced by scholarly debates in organization theory that argue that new institutional theory is 'weak in analysing the internal dynamics of organizational change' (Greenwood \& Hinings 1996: 1023). Hence, rather than focusing on organizational homogenization, scholars seek to explore the 'different strategic responses that organizations enact as a result of the institutional pressures towards conformity that are exerted on them' (Oliver 1991: 145). Consequently, attention is increasingly paid to variations in how NPOs react to and cope with changes to the conditions for their existence and activities (Barman 2002). Researchers identify how organizations present a repertoire of reactions to the challenges of incorporating conflicting logics that come with institutional pressure to comply with an environment dominated by public institutions (Anheier 2000; Arvidson \& Lyon 2014; Leiter 2013; Townley 2002; Turco 2012). Strategies include avoidance, compromise, and manipulation (Oliver 1991), and these variations in organizational response are understood as results of a combination between the characteristics of the isomorphic pressure, the surrounding institutional field, and internal organizational features (Barman \& MacIndoe 2012; Pache \& Santos 2010).

Although rich in volume, and with an overall focus on organizational change, research on NPOs does not on the whole discuss the concept of change per se. In the broader literature on organization theory, however, we find debates that criticize how we have come to assume that change is largely an out-of-the-ordinary condition, and stability is seen as the norm (Tsoukas \& Chia 2002; Weick \& Quinn 1999; Wetzel \& Van Gorp 2014). Although the idea of the organization as a tightly coupled unit may have been abandoned as organizations are increasingly complex in terms of diversity of tasks, group compositions, geographical spread, and connected to a web of stakeholders, it is argued that 'stability, routine and order' (Tsoukas \& Chia 2002: 567) is seen as the norm, whereas change is not. Academic debates have for a long time grappled with the definition of organizational change (Wetzel \& Van Gorp 
2014; Pettigrew et al. 2001) and how it relates to process, continuity, routines, and creativity (Chia 2002; Jarzabkowski 2008; Langley 2011; Tsoukas \& Chia 2002). This has resulted in theoretical developments that, ideally, facilitate the way we conceptualize and research organizational change. By incorporating insights generated from these debates, this article aims to contribute by offering new ways of thinking about change and non-profit organizations. The article presents an analytical framework that proposes an alternative way of theorizing and identifying change to that of institutional theory and isomorphism, with focus on movement and reflection as the mechanisms of change as opposed to a perspective that emphasizes institutional pressure, conflicting logics and formal strategies for coping.

\section{Change and Tensions in NPOs: A Framework for Analysis}

The framework we propose here for understanding organizational change is inspired by two interlinked ideas within organization studies. The first refers to the concept of 'organizational becoming' (Tsoukas \& Chia 2002). A conventional approach to organization and change assumes that the organization is 'punctuated with a few episodes of change' (Bouchikhi 1998: 218), and research taking this perspective consequently aims to describe and analyse organizational life according to input-process-output models (Van de Ven \& Huber 1990). As scholars attempt to incorporate a more comprehensive and realistic understanding of organizational life, 'change and continuity' are increasingly discussed as a conceptual pair (Jansson 2013), where 'change' is no longer presented as a something that reaches an end stage (or closure) but as a continuous process (Tsoukas \& Chia 2002). Whereas change is typically defined as 'a temporal state between two stable moments of a specific organization' (Wetzel \& van Gorp 2014:122), the 'organizational becoming' perspective emphasizes how change consists of 'indivisible continuity,' movement, and flow (Tsoukas \& Chia 2002). This approach suggests that we conceptualize 'organization' as a verb, that is, a social process that is only seemingly stable (Chia 2002), as opposed to a more conventional interpretation of organization as a social entity (Van de Ven \& Poole 2005). While change is continuous, it can take on different characteristics and one way of expressing this is through identifying evolving change as different from episodic change (Weick \& Quinn 1999). These different connotations express temporal differences, i.e. differences in the rhythm and rate of change, as well as differences in the experience and impact of change (Dawson 2014). Whereas evolving change is cumulative and allows for control and reflection, episodic change is related to risks, paralysis, and discontinuity, before the organization enters a transitional phase characterized by intentional restructuring (Weick \& Quinn 1999).

The second idea that informs our framework is about how the organization is increasingly viewed as a 'juxtaposition of opposing forces' (Graetz \& Smith 2008: 266) rather than a homogenous unit. The concept of organizational dualities can be related to different dimensions of organizational life. Apart from tensions/dualities emanating from interaction with the environment (e.g. as seen in the research on competing logics), we also find them within the organization, represented by, for example, the relationship between managers and employees, where managers seek to impose 'control strategies', while employees constantly elaborate on 'autonomy-seeking strategies' (Bouchikhi 1998: 219). Studies also illustrate how tensions are intrinsic to organizational life, for example, the inherent dilemmas of altruistically motivated actions often ascribed to organizations with an origin in volunteering and charitable activities (Arvidson 2008). Studies that aim at outlining 'how-to', prescriptive scenarios about change management with the view to achieve smooth operation tend to ignore how dualities, ambiguities, and paradoxes are simultaneously sources of conflict and creativity, change and stability (Sturdy \& Grey 2003) and how identifying the sources of tensions is key to understanding organizational learning and development (Evans 1999; Graetz \& Smith 2008). Rather than associating organizational tensions with conflicts and mismanagement, polarization and disputes (Evans 1999), Graetz and Smith (2008) argue for dualities and tensions to be recognized as associated with 'relational, synergistic tendencies' (p. 266). Hence, while dualities and ambiguities may on the one hand provoke conflict, they also invite for creativity and innovation (Evans 1999). At the centre of this lies an understanding that reflection, prompted by tensions and ambiguities, at individual and collective levels, underline changes.

Embedded in the debates above, we find calls for what Pettigrew et al. (2001) refer to as a 'new pluralism' in the study of organizational change, and an end to what Wetzel and Van Gorp (2014) call dull and repetitive organization change research that does not reflect the theoretical diversity available today. There are also suggestions for fundamentally new ways of understanding organizations and change. For example, Chia (2002) argues that it is 'organization that is the exception' and change is the norm, and as a consequence organization studies must look beyond the organization as an 'economic-administrative unit' and instead focus on organization as 'world making' (p. 867). In other words, the debates allude to essential and challenging issues that concern the application of new 
theoretical insights to empirical research as well as an inverted perspective on the relationship change/ organization.

Our proposed analytical framework is an attempt to translate these ambitions - to generate new understandings of organizations and change-into an empirically applicable tool. The framework should be seen as one step towards establishing an alternative way of researching NPOs from a perspective that emphasizes motion, friction, and reflection as the fundamental elements of change, which differs from one informed by new institutional theory that emphasizes institutional dominance and asymmetric power as driving forces of organizational change. Inspired by the two interlinked strands of theoretical debates outlined above, the framework is based on the distinction between different types of change-evolving and episodic-and different sources of tension-inherent dilemmas and conflicting logics. The framework also involves a way of conceptualizing the organization as movement based on the identification of multiple processes related to the four categories. The analysis contributes to current research on NPOs by challenging our perception of service-delivering NPOs that operate in close proximity with the public sector. Change in this context is typically ascribed to the meeting between organization and overarching institutional framework, and to strategic decisions taken in order to maintain balance between organizational autonomy and external control. Furthermore, the framework contributes by challenging the way change is associated with organizational tension. Changes may exacerbate existing tensions, but a focus on change as the attributing factor may mask tensions and dilemmas that are integral to organizations in general, and specific to the type of work this non-profit and charity-based organization is involved with (Fig. 1).

Evolving change consists of interactions and dialectic processes that do not necessarily follow a linear pattern (Jansson 2013; Jarzabkowski 2008; Langley 2011). Furthermore, it assumes that the response to evolving change is not primarily resistance and avoidance, which are aspects highlighted in the literature on NPOs influenced by new institutional theory, but also reflective negotiation by actors seeking to find/make space for core organizational values and principles in new contexts (Battilana \& D'Aunno 2009). Change as an evolving, iterative process may be driven by a striving to implement or retain a set of principles in spite of challenges and hindrances, but is not based on a specific strategy or agenda (Pettigrew et al. 2001: 704). Pettigrew et al. (2001) define episodic change as 'changes that tend to be infrequent, discontinuous, and intentional' and that occurs as 'a result of misalignment or environmental encroachment' (p. 704). The definition applied here follows this on the whole: it aims to capture

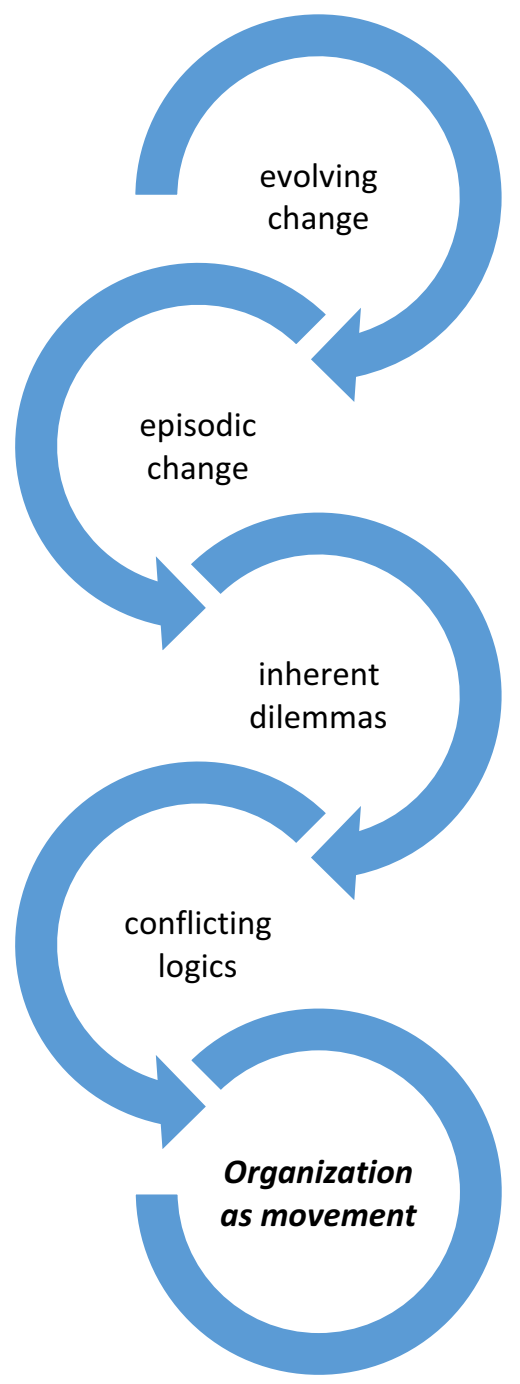

Fig. 1 Key components of the analytical framework

change that is experienced as an event, an incident that sets a period aside as different to other periods. Change is both intentional, as in a strategically planned move, and unintentional, as in the result of reactions to this planned change and/or to events in the environment.

The second dimension of the framework elaborates on the concept of tension, which signifies frictions that are not necessarily hostile or conflictual by nature, and it is exemplified by inherent dilemmas and conflicting logics. A dilemma presents the organization and its staff with a conundrum where actors seek some level of satisfaction in the way a problem is handled, but the issue as such cannot be solved. Dilemmas arise as a consequence of inherent shortcomings of principles, values, and commitments agreed by staff and organizations (see e.g. Frick 2009). Organizations can be described as 'dilemmatic spaces' where, for example, 'authority' and 'empowerment' both constitute leading principles behind social work (Hoggett 
2006). Finally, the second dimension identifies conflicting logics as an important source of tensions. The concept of organizational logics is described as 'cultural templates that provide the organizational actors with means-ends designation as well as organizing principles' (Pache \& Santos 2010: 457). The idea of conflicting logics refers to a well-rehearsed theme in studies of NPOs: public sector logics and charitable, non-profit sector logics do not correspond. Research tends to emphasize the coercive power of the public institutional logic leading to a mainstreaming of NPOs in structure, goals, and means of operating (DiMaggio \& Powell 1983). A general critique against this perspective is that it assumes conflict and hostility between (representatives of) logics, and that one logic must 'win' (Graetz \& Smith 2008). But instead of perceiving conflicting logics as causes of polarization and disputes within the organization, they can be considered as dualities that underpin constructive tensions (Evans 1999; Graetz \& Smith 2008) and hence a source that contributes positively to organizational integrity and the strengthening of organizational identity.

\section{Method and Empirical Context}

The empirical material is based on a longitudinal qualitative study conducted over a period of four years (20102013), involving one case study organization based in England. The core research questions concerned with what happens within third sector, non-profit organizations over time and why; what matters to NPOs over time and why; and how might we understand continuity and change in NPOs (Macmillan 2011). These questions were prompted by an identified lack of studies that allow for an understanding of how policies and politics at micro- and macrolevel affect NPOs working with social welfare services. The protocol for the study was based on a pattern of sixmonth interaction with the case study organization, assuming that a six-month interval would allow for the identification and tracking of both continuity and change. Each wave of interaction included interviews with key individuals of the organization, in total 16 interviews: the same individuals were interviewed on repeat occasions, with the exception of the CEO, because the CEO position was occupied by three different individuals over the period of study. It also involved participant observations in the organization's activities, participation in meetings, informal conversations with staff during the visits paid to the organization and its activities. Throughout the study, I gathered and examined documents of relevance (from the organization in question and the local municipality with which the organization was closely linked). To gain further insight into the organizational context, I interviewed individuals working for organizations (other NPOs, municipality) with which the case study organization was closely engaged.

The purpose of the analysis is to facilitate new ways of thinking about change and tensions in NPOs and as a result deepen our understanding of these organizations. The analytical work is based on an iterative process where time, research relations, and extended theoretical insight interact, with the aim to gain analytical refinement (Ponterotto 2006; Tsoukas 2011). The components of this iterative process are linked to the opportunities offered by the longitudinal case study approach as it offers a possibility to engage critically with the organization's presentation of change, how change and tensions contribute to confirmation as well as the unsettling of organizational identity. The first waves of engagement resulted in stories about structured, strategic ways of dealing with planned as well as unanticipated change. Stories represented 'formalized organizational narratives' (Taylor et al. 2014: 54) that forwarded an image of a strong organization with integrity and direction, in spite of it being exposed to changes enforced by a dominating public sector and a volatile political reality. The impression was also that these stories were aimed at presenting 'a desirable image towards us as researchers' (Dey \& Teasdale 2016: 491). As the study continued and the researcher was 'becoming more sophisticated and knowledgeable about past histories' (Dawson 2014, p. 140), interviewees appeared to regard their 'audience' differently. From taking measured, sometimes cautious, approaches to the interview, interviewees came to share critique and confusion concerning the future of the organization, its leadership and their own positions and actions. This changed the basis from which interviews were carried out, resulting in joint probing into issues of change, dilemmas, conflicts, leading to more generous accounts of organizational work (Hermanowicz 2013). As differences in views and interpretations of events became clear, this probing formed the basis for active interviewing and joint meaning-making (Holstein \& Gubrium 2004). In this way, the longitudinal aspect allows for competing stories and experiences related to change and tension to emerge and it offers an experience that benefits critical examination of both empirical data and theoretical concepts (Dawson 2014).

The changing nature of the interaction between researcher and interviewee is central to the material presented here as it moved focus from change related to the external environment with emphasis on the presentation of the organization as struggling yet competent, to narratives that reveal organizational tensions of different origins and that involved different dynamics. The interviews took on a nature of contemplating, reflecting on, rather than stating things that had occurred since we last met. Hence, the value 
of the longitudinal case study approach also lies in the possibility, or rather necessity, to continuously question theoretical perspectives that underpin the study and to seek further, different, theoretical views (Tsoukas 2011). In this case, the initial theoretical framework was strongly characterized by new institutional theory and the concept of isomorphism, with the view to observe processes of homogenization and/or variation in the way the case study organization responded to changes in its environment. Initial analysis suggested that this could be interpreted as a case of an organization going through isomorphic changes albeit with different elements of variations, some sustainable and others not. However, the longitudinal engagement with the empirical field combined with new theoretical perspectives on organizational change led to a more refined understanding of the organization as such, and not only change. As a consequence, this required a more diverse conceptual toolbox that would allow for an analysis that recognizes change and tensions of different natures (see Ragin 1992).

\section{Background: The Case Study Organization}

The case study organization is an English organization, a registered charity and company limited by guarantee, supporting individuals in the area of mental health and social care. It offers a range of services for individuals suffering from long- and short-term mental health problems. The organization has roots in community action and volunteering. Established in the 1960s, the organization was initially run by a small group of people living close to and working at a psychiatric hospital, who wanted to do something to support its patients in other ways than that offered by the statutory psychiatric institution. Initially, funding came primarily from individuals or grant giving bodies. Until the mid-1980s, it was run entirely by volunteers, including doctors and counsellors. The demand for community-based activities increased with the closure of psychiatric wards and the organization grew as a result. Since its inception, it has developed to become a service delivery organization with close connection to mainstream public services. The yearly turnover is now around $£ 500 \mathrm{~K}$ with funding primarily from local authorities. The organization employs around 30 people, including a core of three to four senior managers, and engages a team of volunteers. Data for the period 2008-2012, which concern annual income, main source of income, annual expenditures and staffing, show relative stability (Table 1 ).

The organization has engaged with rationalization as prescribed by new performance management regimes, and in its own words it has become 'more professional': management, monitoring, evaluation, quality assessment, and professional training and accreditation are all concepts that suitably describe how the organization is operating now. Its view of and engagement with its environment has changed too. It was initially driven by needs as expressed by clients and carers, and as experienced by staff engaged professionally with clients. Now, the chief executive and senior managers put great emphasis on networking with local authorities, commissioners, and other organizations operating in the same service delivery field. The purpose of this is to influence and understand local interpretations of national policies, to predict tenders and trends in how local authorities plan for short- and long-term future of service delivery, and to make sure that what they offer is seen as professional, distinctive, high-quality services. This interaction with surrounding actors has over the years become increasingly intense, and the organization's services are now often incorporated into clients' statutory care plans, which involve meetings on a regular basis with care coordinators, social workers, psychiatrists, and GPs.

The services and support the organization offers reflect what has been identified as shortcomings in both what statutory services are available and how these are delivered. In their goals, the organization emphasizes the importance of offering client-centred services through active service user consultation and involvement in the organization at every level. Staff describe how they are non-judgemental and non-prescriptive, and that this distinguishes the organization from statutory services. We are highly committed to working with people. [...] to represent the vulnerable, those who are unable to represent themselves, to support people who find that difficult. Peter further defines what this commitment means by saying 'We put people first. It's a key thing to be non-judgemental'. These values and principles form an important basis for our understanding of the narratives below.

The organization is working along a strategy that involves delivering services that are at the same time mainstream, versatile, and specialized. In practice, this means making sure they relate closely to statutory, mandatory services that are at less risk of being cut, but at the same time finding a niche market that they can use to create a strong profile as being different from competitors. The difference in role and position of the organization in relation to public sector activities is not entirely easily to see: 'I sometimes think we often work like a statutory service' reflects Eva, and goes on to add that they provide statutory services, but the fact that they do so in a different framework, and with core services integrated with each other, and with additional activities to offer, makes them different. Bob describes it as 'providing, essentially, cut rate statutory services with a slightly different flavour'. For the uninformed, the services provided by the organization may appear identical to those delivered by public service bodies. But, Bob continues 'we're not just a complete 
Table 1 .

\begin{tabular}{|c|c|c|c|c|c|}
\hline & 2008 & 2009 & 2010 & 2011 & 2012 \\
\hline Annual income & $£ 599,653$ & $£ 628,685$ & $£ 597,989$ & $£ 638,942$ & $£ 698,669$ \\
\hline $\begin{array}{l}\text { Main source of } \\
\text { income }\end{array}$ & Grants $£ 477,227$ & Grants $£ 512,264$ & Grants $£ 515,264$ & Grants $£ 491,127$ & Grants $£ 449,017$ \\
\hline $\begin{array}{l}\text { Annual } \\
\text { expenditure }\end{array}$ & $£ 632,973$ & $£ 584,273$ & $£ 523,361$ & $£ 593,881$ & $£ 521,212$ \\
\hline Spent on staffing & $\begin{array}{l}£ 463,284 \text { ( } 30 \text { paid } \\
\text { employees) }\end{array}$ & $\begin{array}{l}£ 409,598 \text { ( } 29 \text { paid } \\
\text { employees) }\end{array}$ & $\begin{array}{l}£ 391,435 \text { ( } 27 \text { paid } \\
\text { employees) }\end{array}$ & $\begin{array}{l}£ 386,409 \text { ( } 26 \text { paid } \\
\text { employees) }\end{array}$ & $\begin{array}{l}£ 367,969 \text { ( } 26 \text { paid } \\
\text { employees) }\end{array}$ \\
\hline
\end{tabular}

substitute' and explains that 'we're not subject to some of the constraints that a statutory service is. We can be a bit more innovative and users like us more because they don't feel they are going to - one step away from hospital, sort of thing'. The very same reference to what distinguishes the organization from public sector is given by the chief executive: the organization is providing space to reflect for clients, 'away from the idea of sectioning and control by the state'. It seems the similarities between sectors are deceptive: the way and the context in which the very same services are delivered make all the difference.

\section{Evolving Change}

The organization of today has come about as a result of a range of changes around the organization. Bob, who has been working for the organization as a trustee since its inception, explains how 'the scene has changed' referring to national policies directly aimed at the third sector and to policies that change the position of the organizations constituency (client groups). These changes interact with changes from within the organization-based on knowledge and understanding produced through close interaction with clients. Eva, a counsellor, says 'We have changed so much' and refers to the organization as a whole, its staff, the services offered, and the interaction with clients. Although sometimes prompted by changes in surrounding policies, Eva maintains that change has been driven by the initiative of staff, based on experience and interaction with clients.

The way Eva and colleagues discuss change reveal that although fundamental, changes have not necessarily been experienced as interruptive or forced: change came about as a result of being client-led, of continued collective reflection. The narratives emphasize growth in terms of maturity and expertise driven from within the organization rather organizational change as a result of pressure from outside. The force of the external environment is, however, noticeable, as the organization is dependent on both funding and social welfare policies implemented by the local council. Staff has become skilled in tempering change prompted by financial insecurity, policy changes, or change of staff within the municipality that seem to have a different take on collaboration across sectoral lines, through 'containment', as Eva explains: 'it's the ability to hold things whilst the change is going [on]'. One of the CEOs summarizes the balance between driving change and managing the conditions set by events and actors outside of the organization:

You can resist change to a certain extent but, if the change is going to happen regardless, you have to consider where you could fit with the new arrangements. So that's what we continue to do and that's why I say it's always this process of evaluating things and change. Just the external environment is dictating that to some extent.

Evolving change, in other words, signifies relative equilibrium with a mixture of containment while assessing how institutional pressure to change in order to keep up with the external world can be managed, and change that is an expression of intrinsic forces based on organizational principles and accumulated knowledge.

\section{Episodic Change}

Episodic change is defined as change that 'occurs during periods of divergence when organizations are moving away from their equilibrium conditions' (Weick \& Quinn 1999: 365). Such 'divergence' may happen due to change in technology that fundamentally alters production processes, or change of key personnel that have implications for relations and strategies. The example provided from the organization originates in the sale of two properties, with activities and staff split between them, and the consequent move to and renovation of a new building that would house the organization as a whole. This change was planned, but it set in motion radical changes at individual as well as organizational levels. The CEO became absorbed by the 
process: It's all very exciting but it's been incredibly time consuming and incredibly stressful she recounts and reveals how she has had to sacrifice being involved in other essential issues related to the development of the organization.

The relocation to new premises has meant an opportunity to modernize facilities, improve access to services, and facilitate the interaction between groups of staff on a more frequent basis. However, the positive implications are yet to come into fruition as the main concern regarding financial insecurity is at the forefront of every ones' mind. Catherina, the CEO, explains that as a result of the sale of their two buildings generating 'less than we were hoping for' combined with escalating bills for building costs 'we have got about a $£ 200,000$ deficit on the project at the moment'. The financial situation is worrying to other staff who question the way the CEO and Board of Trustees are handling the situation: 'I think we're haemorrhaging more money, which seems a bit odd when they've sold both buildings' (Kimberley) (Table 2).

The move and consequent financial insecurity has a sudden impact on work structure and intra-organizational relations with mounting tensions due to worries and disagreements. As a direct measure to curb further budgetary shortfall, the CEO is focusing on setting up incomebringing activities. She explains how they should try to ' $d o$ some more entrepreneurial stuff', one of which involves a 'move into residential care because I think its nice reliable money'. Although this is part of a vague long-term plan, it requires urgent action in order to ascertain some initial investment. Hence, the CEO plans cut budget allocation to some of their services by way of reducing overheads. This involves transferring administrative work tasks to staff who, by the previous CEO, are described to be 'at breaking point'. Furthermore, the present CEO is herself reducing her hours from full-time to part-time and has engaged an external consultant to explore ideas for fund raising. Ideas about new income-bringing services include approaching private employers and HR managers in the local area, offering counselling services for employees. This, and other initiatives for costs cutting and fund raising, has caused disagreements: it affects individual staff, organizational structure, and the values and principles on which the organization builds. Rather than pushing for quick solutions to budgetary problems, it is important to 'have a structure in place that's fair and ethical' explains Kimberley, referring to what she considers to be thoughtless plans involving the use of volunteers working for free offering services the organization will charge for. There are frequent meetings regarding short- and long-term strategies and Kimberley experiences continuous tensions during these meetings: '... I feel sometimes I talk and they look at me, and I feel I'm the, sort of, Jonah sort of thing' implying her comments are not welcome.

This episodic change is set off by the move from premises with the view to eventually establish a more coherent and self-sustainable organization. However, the move has set off a range of unexpected events that involve tensions due to anxiety and disagreements within the organization.

\section{Inherent Dilemmas}

As is evident in the narratives above, there are tensions within the organizations. Some of these are inherent to social work as explored through the concepts of professional discretion (Lipsky 1980), and 'dilemmatic space' that summarizes the predicament of simultaneously working 'in and against authority' (Hoggett 2006). The following example arises as a result of a clash between, as Peter puts it, 'textbook' and 'reality', where professional guidelines reflect a focus on the relation between client and staff, but ignores the context in which these guidelines are practiced. Peter's job involves close and frequent interaction with staff from other organizations, primarily from statutory organizations. Staff have extensive networks with professionals of various background (statutory counsellors, district nurses, medical doctors, and the police) that for different reasons come into contact with their clients. Peter recounts:

So, we're non-judgmental ... we put people first. It's a key thing to be non-judgmental. It can be [tough to follow]. ... I was in my office once. A female patient came to me and said - Peter, if I make a complaint about my consultant would that help me change him? She went away, and a few days later she came back and said to me, I want to make a complaint about my doctor because he touched me inappropriately. Now because she came to me a few days before I couldn't help but wondering. Is this a genuine complaint or is she just making this complaint in order to help her change her consultant? But my job is to act on the clients instructions, to be non-judgmental, so no matter what I thought about that, I helped her to do it.

Table 2 .

\begin{tabular}{llllll}
\hline & 2008 & 2009 & 2010 & 2011 & 2012 \\
\hline Annual income & $£ 599,653$ & $£ 628,685$ & $£ 597,989$ & $£ 638,942$ & $£ 698,669$ \\
Spent on buildings & - & - & - & $£ 467,920$ & $£ 881,029$ \\
\hline
\end{tabular}


It turned out he was one of my favourite consultants, but you know, I had to do it.

The situation was upsetting: Peter had to prioritize his work principles and disregard the possibly serious consequences his actions could have for a consultant he likes and respects. In another example, Peter illustrates how the client-led and non-judgemental principles seem to ignore him as a knowledgeable agent. It does not allow him to comment or intervene with instructions given by his clients. He values the principles and they seem truly embedded in how he sees his professional role as well as in his own beliefs of what is important for the people he represents. Yet, they put him in difficult situations when he recognizes that the consequences of following his clients' instructions may not be in their best interest:

Another time... I was invited to a patient, an outpatient. [...] don't forget: we are client-led; we act on the client's instructions. She wanted me to basically support her in resisting the social worker's demands. I told her they [social workers] are not trying to take your child away, they are trying to keep you together. I couldn't help but say to her that I think this is something you should take! Now, I said that to her and I was strictly out of my role and I know that I was out of my role. I phoned my manager at the time and I told him what I had done, just in case a complaint came back because that is not how we should be working. ... It's like a dilemma, you know, you have different roles and that's how you do it by textbook but actually in reality it doesn't work like that.

In order for Peter to carry out his job in a satisfactory way, he needs to build up networks based on trust and legitimacy with surrounding professionals from other institutions. Yet, he is forced to ignore the values underpinning this trust and legitimacy in order to fulfil the values driving the client-led approach that advises him to be nonjudgemental and to steer clear from imposing his own views and interpretations on his client. We can define these tensions as inherent: once values and principles are translated into action, ambiguities are revealed leading to ongoing dilemmas.

\section{Conflicting Logics}

The concept of conflicting logics relates to a well-established theme in research on non-profit organizations. The following example brings out how conflicting logics coexist as a consequence of the organization operating on the boundaries between statutory and non-profit-based social welfare work.
The organization's work is based on a set of directives that come from values of being non-judgemental and client-led. This clashes with directives based on the principles of safeguarding and 'duty of care', emphasized by local authorities and that the organization must relate to due to service delivery contracts. We can frame this as conflicting institutional logics. Staff recounts how the conflicting logics place them in dilemmatic situations. Peter works with mental health advocacy, which offers clients representation and support without judging them or prioritizing professional opinions. His position is different to staff in public organizations working with the very same client, since statutory staff have a 'duty of care' which means they would not support a client's wishes if they think it may be bad for that client. What is considered 'bad' is by and large stated in guidelines they are required to follow and that have precedence over client, or staff, preferences. These differences are clearly expressed in the concepts of 'clientled' versus 'safeguarding' (see Safeguarding of Vulnerable Groups Act 2006).

Peter describes a dilemma he faces on a frequent basis as a consequence of these overlapping instructions. It arises from personal, professional, and organizational commitments conflicting with rules and regulations that come with operating within the context of institutional logics set by the statutory sector. The essence of these examples is captured in the following:

So if there is a suspicion that they have been abused or exploited [...] we must notify the safeguarding officer. Now that puts us in a quandary because we are client-led and if a client says to me, look, I don't want you to say anything about this, then normally we would respect that. But to provide advocacy in this borough - we have to sign up to safeguarding policies ... so we have to report it.

Although Peter and his colleagues 'have to report it', they later describe how they have come to treat some communication with clients as off the record. During informal discussions with Peter and his colleagues, they continuously articulate how they work towards building client relations based on trust that they remain non-judgemental. Being faced with a set of logics that come into conflict with this is used to refine their own values and to identify ways of practicing the 'client-led' principles in spite of reporting requirements. Furthermore, the staff describe how they use markers in their communication with clients such as 'you know I will have to report this' to share their distinction between who they are as an organization and the role they take on as providers of statutory services. So the 'quandary' caused by them 'having to report it' is used to identify collective values, and it is solved by decoupling the dual roles the staff inhabit as 
organizational representatives and deliverers of statutory services.

\section{Discussion}

The longitudinal research design invites a focus on processes that follow a chronological, progressive trajectory. Mapping such a trajectory is important, not the least as a concrete point of reference when trying to understand the journey of an organization over time. However, the analytical ambition is to forward a notion of change that integrates different kinds of processes, chronological and other, that make up the 'organization as movement'. The longitudinal approach allowed for interviews to take on a character of reflection where interviewees revealed interpersonal conflicts, personal uncertainties, and thoughts that involved 'if-then' scenarios in relation to organizational principles in new settings. While describing events in chronological orders, interviewees contemplated on processes of emotional and cognitive character, at individual, organizational, and institutional levels. In this way, the material offers important insights to the concept of organization as movement.

The conceptual pair 'change and tensions' embodies the organization as movement. On the one hand, the analytical framework invites for descriptions of processes that have horizontal, linear trajectories. On the other, the stories include processes that resist this notion of horizontal movement and rather refer to processes on cognitive and emotional levels. In the stories categorized as evolving and episodic change, we find references to time as in past events and movement forward. These time-bound stories include multiple processes that run in parallel, include alternative, opposing change paths and that all contribute to an ever-evolving organizing process (see Langley 1999, 2011). These are coupled with processes of negotiations and conflicts that concern future trajectories. In the empirical material, staff refer to how the organization is 'always in a crisis', 'go with the flow', and 'contain' things. Staff reveal conflicts as alternative paths to address acute financial issues were negotiated with some seeking to develop 'entrepreneurial stuff 'and others worrying about solutions not being 'fair and ethical'. During the fieldwork, it was notable how anticipation of change (if project applications were approved, when the new CEO took up her position) influenced individual's perceptions of the organization as a whole, colleagues and their own roles. This implies that staff are continuously occupied by processes of assessing risks and opportunities related to change whether past, ongoing, or imagined. The interviewees describe how they relate to the notion of change with both discomfort, as control is not in their hands, and faith, as with time things will settle into good routines. The way interviewees discussed change revealed that although some strategies may be labelled passive and submissive, they are at the same time active decisions that require reflection, experience, and skills: knowing when to go with the flow, how and when to contain things. This suggests a complex relationship between change and stability.

While the descriptions of change above contain references to emotional and cognitive processes, the narratives shared under the tension categories illustrate such processes even clearer. These processes are associated with dilemmas and interactions and although they have an element of a striving to resolve issues, a movement forward, they rather recognize how ever-changing contexts render closure difficult to achieve. Processes relate to relations between rhetoric and practice, between clients and professionals, different professional groups, and between institutional logic and organizational principles. Peter's stories include experiences of conflicts and tensions in relations with clients and colleagues. He describes personal shortcomings, he makes mistakes, but more importantly he identifies how principles and values carry inherent conflicts that are not resolved, once and for all, but require continuous assessment of new situations. Peter's reflections concern the different meanings of trust and of being nonjudgemental depending on context. The challenges presented by relations (with reality, with clients, with colleagues) stimulate reflection: over the period of the study Peter revisited stories about dilemmas associated with relations and it emerged the ongoing reflections supported him in defining the values he chose to work from.

The conceptual pair of change and tensions as applied here allows for multiple processes to be identified and understood as separate yet interlinked (Fig. 2). The distinction between change processes from within the organization and change as a result from external pressure becomes blurred. And whereas some processes refer to a linear change trajectory, they are closely interlinked with cognitive and emotional processes. A central theme throughout the stories is reflection: a key mechanism of change is the reflexive capacity of individuals and collectives as they are faced with new experiences. Being right at the edge of sector boundaries is challenging as it creates 'unique challenges for the maintenance of organizational integrity' (Dacin et al. 2002). Such challenges are clearly expressed in the narratives. However, these challenges also appear to encourage a 'reflecting capacity' of actors within the organization (Battilana \& D'Aunno 2009) and hence become key to organizational and professional identity, integrity, and pride. Likewise, tensions due to ambiguities, conflicts, and dilemmas operate as sounding boards as staff manoeuvre the meaning of principles and identity linked to the organization's inception, in a reality that continuously 


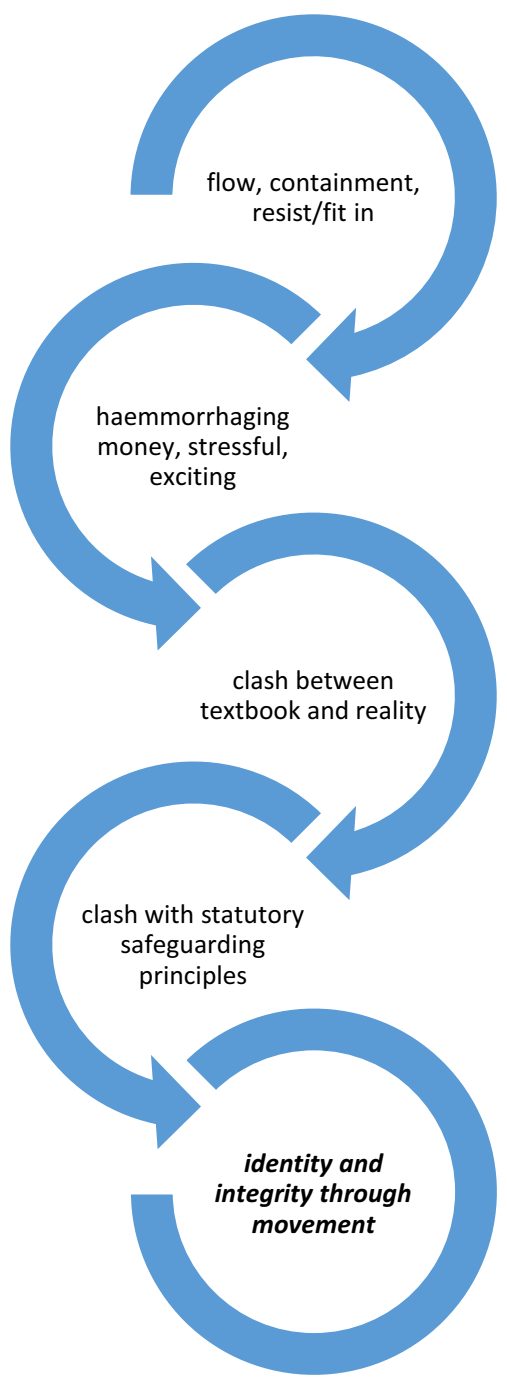

Fig. 2 Key components illustrated

presents staff with new settings. This corresponds well with the view that the organization is 'an outcome, a pattern, emerging from the reflective application' of organizational principles that on the large remain the same but are applied in ever-changing contexts (Tsoukas \& Chias 2002: 570). Based on this, the argument for an inverse perspective on the relationship change and organization wherein the concept of organization rather than change is analysed (Chia 2002) may be easier to accept. This analysis also resonates well with debates reviewed above that concern organizational dualities and that maintain that tensions and ambiguities must be understood as the basis for reflection leading to innovation, creativity, and consolidation of organizational integrity (Evans 1999; Graetz \& Smith 2008; Sturdy \& Grey 2003). The explanatory power of the conceptual pair 'change and tensions' comes from how the analysis supports an understanding of the reciprocal relationship between change/tensions and reflection, and how, in this case, this reflection appears to encourage reconnection with organizational values.

\section{Conclusion}

Recent literature on non-profit organizations has established that there is wide variation in how organizations respond to institutional pressure. Yet, few studies go beyond the theoretical frames of new institutional theory which emphasizes institutional dominance and asymmetric power as the key elements of organizational change. Through the conceptual pair of change and tensions, the analytical framework applied here integrates two debates central to organization studies that seek to challenge conventional theories of organizational change and tension. The debates concern the concept of 'organizational becoming' (Tsoukas \& Chia 2002) and the idea that organizations are made up of opposing yet relational forces rather than homogenous units (Graetz \& Smith 2008). The contribution of the article to scholarship on non-profit organizations lies in the attempt to expand our understanding of the concept of change based on these debates. The study also contributes to scholarly debates in organization studies by taking on the challenge of translating alternative theories of change to an empirically applicable tool. Scholars argue that empirical studies tend to refer to a rather narrow set of theories, although there is a range of theoretical concepts and propositions at hand that concern organizational change (Pettigrew et al. 2001; Wetzel \& Van Gorp 2014). In both cases, contribution has been enabled by the longitudinal case study as an exploratory approach where new theoretical concepts have simultaneously shaped the analysis of and interaction with the field. Furthermore, identifying and applying the conceptual pair of change and tensions has proven fruitful as it supports a categorization of processes that can be understood as based on distinct sources yet are interlinked through individual and collective reflections on organizational life. The analysis illustrates a way of incorporating processes that are linear, progressive in character, with cognitive processes wherein interviewees reflect on alternative scenarios and actions at individual and organizational level.

The analysis is inspired by the argument that it is through focus on reflection rather than on "practical matters' (Tsoukas \& Chia 2002: 572) that we can understand a complex reality. Hence, the focus in the presentation on the reflective processes as key elements to our understanding of organization, change and tensions. Whereas this has enriched our understanding of the meaning of change and tensions in this particular organization, the study naturally has limitations. The case study organization does not represent the ideal-typical non-profit organization, as it is 
highly formalized, professionalized, and displays marketlike strategic thinking as it asserts itself as a competitive service provider. Neither the organization nor the quotes are representative in the sense that they offer a basis for a universal understanding of NPOs. But we can assume a potential generality of the results: the case study organization has some general features of NPOs operating in similar contexts. Regarding the framework and the analytical approach, questions remain about how this can contribute to more specific theorization of change that underpin not only understanding and explanation of particular case studies, but also have the ability to map predictions of organizational movements (Langley 1999). Processes that originate in relations, interdependences, inherent dilemmas are the foundations for reflection and identity formation. A future research agenda can develop this argument by exploring if particular sets of processes and organizational preconditions encourage reflexivity (Chia 2002), how this can be linked to organizational performance (Pettigrew et al. 2001) and patterns of distinct 'methods of adaptation' (Brandsen \& Karré 2011) that are particular for organizations such as the one examined here, that finds itself in a position that embodies institutional complexity.

Acknowledgements This research for this paper was done as part of a programme of the Third Sector Research Centre (TSRC), University of Birmingham, UK. The support of the UK's Economic and Social Research Council (ESRC), the Office for Civil Society and the Barrow Cadbury UK Trust is gratefully acknowledged.

\section{Compliance with Ethical Standards}

Conflict of interest The author declares that there is no conflict of interest.

Open Access This article is distributed under the terms of the Creative Commons Attribution 4.0 International License (http://crea tivecommons.org/licenses/by/4.0/), which permits unrestricted use, distribution, and reproduction in any medium, provided you give appropriate credit to the original author(s) and the source, provide a link to the Creative Commons license, and indicate if changes were made.

\section{References}

Anheier, H. K. (2000). Managing non-profit organisations: Towards a new approach. London: Centre for Civil Society, London School of Economics and Political Science.

Arvidson, M. (2008) Contradictions and Confusions in Development Work. Journal of South Asian Development 3(1), 109-134.

Arvidson, M., \& Lyon, F. (2014). Social impact measurement and non-profit organisations: Compliance, resistance, and promotion. Voluntas, 25(4), 869-886.

Barman, E. A. (2002). Asserting difference: The strategic response of nonprofit organizations to competition. Social Forces, 80(4), $1191-1222$.
Barman, E., \& MacIndoe, H. (2012). Institutional pressures and organizational capacity: The case of outcome measurement. Sociological Forum. https://doi.org/10.1111/j.1573-7861.2011. 01302.x.

Battilana, J., \& D'Aunno, T. (2009). Institutional work and the paradox of embedded agency. In T. B. Lawrence, et al. (Eds.), Institutional work: Actors and agency in institutional studies of organizations. Cambridge: Cambridge University Press.

Beckert, J. (2010). Institutional isomorphism revisited: Convergence and divergence in institutional change. Sociological Theory, 28(2), 150-166. https://doi.org/10.1111/j.1467-9558.2010. 01369.x.

Bennett, R., \& Savani, S. (2012). Surviving mission drift: How charities can turn dependence on government contract funding to their own advantage. Nonprofit Management and Leadership., 22(2), 217-231.

Billis, D., \& Glennerster, H. (1998). Human services and the voluntary sector: Towards a theory of comparative advantage. Journal of Social policy, 27(01), 79-98.

Bouchikhi, H. (1998). Living with and building on complexity: A constructivist perspective on organizations. Organization, 5(2), 217-232.

Brandsen, T., \& Karré, P. M. (2011). Hybrid organizations: No cause for concern? International Journal of Public Administration, 34(13), 827-836.

Brandsen, T., van de Donk, W., \& Putters, K. (2005). Griffins or chameleons? Hybridity as a permanent and inevitable characteristic of the third sector. International Journal of Public Administration, 28(9-10), 749-765.

Buckingham, H. (2012). Capturing diversity: A typology of third sector organisations' responses to contracting based on empirical evidence from homelessness services. Journal of Social Policy, 41(03), 569-589.

Chia, R. (2002). Essay: Time, duration and simultaneity: Rethinking process and change in organizational analysis. Organization Studies, 23(6), 863-868.

Copestake, J. (2007). Mainstreaming microfinance: Social performance management or mission drift? World Development, 35(10), 1721-1738.

Dacin, M. T., Goodstein, J., \& Scott, W. R. (2002). Institutional theory and institutional change: Introduction to the special research forum. Academy of Management Journal, 45(1), 45-57.

Dawson, P. (2014). Reflections: On time, temporality and change in organizations. Journal of Change Management, 14(3), 285-308. https://doi.org/10.1080/14697017.2014.886870.

Dey, P., \& Teasdale, S. (2016). The tactical mimicry of social enterprise strategies: Acting "as if" in the everyday life of third sector organizations. Organization, 23(4), 485-504. https://doi. org/10.1177/1350508415570689.

DiMaggio, P. J., \& Powell, W. W. (1983). The iron cage revisited: Institutional isomorphism and collective rationality in organizational fields. American Sociological Review, 147-160.

Dolnicar, S., Irvine, H., \& Lazarevski, K. (2008). Mission or money? Competitive challenges facing public sector nonprofit organisations in an institutionalised environment. International Journal of Nonprofit and Voluntary Sector Marketing, 117(May), 107-117.

Eikenberry, A., \& Kluver, J. (2004). The marketization of the nonprofit sector: Civil society at risk? Public Administration Review, 64(2), 132-140.

Evans, P. A. L. (1999). HRM on the edge: A duality perspective. Organization, 6(2), 325-338.

Frick, W. C. (2009). Principals' value-informed decision making, intrapersonal moral discord, and pathways to resolution: The complexities of moral leadership praxis. Journal of Educational Administration, 47(1), 50-74. 
Goodrick, E., \& Salancik, G. R. (1996). Organizational discretion in responding to institutional practices: Hospitals and cesarean births. Administrative Science Quarterly, 41(1), 1-28.

Graetz, F., \& Smith, A. C. T. (2008). The role of dualities in arbitrating continuity and change in forms of organizing. International Journal of Management Reviews, 10(3), 265-280.

Greenwood, R., \& Hinings, C. R. (1996). Understanding radical organizational change: Bringing together the old and the new institutionalism. The Academy of Management Review, 21(4), 1022-1054.

Hasenfeld, Y., \& Garrow, E. E. (2012). Nonprofit human-service organizations, social rights, and advocacy in a neoliberal welfare state. Social Service Review, 86(2), 295-322. https://doi.org/10. 1086/666391.

Hermanowicz, J. C. (2013). The longitudinal qualitative interview. Qualitative Sociology, 36(2), 189-208.

Hoggett, P. (2006). Conflict, ambivalence, and the contested purpose of public organizations. Human Relations, 59(2), 175-194.

Holstein, J. A., \& Gubrium, J. F. (2004). The active interview. In D. Silverman (Ed.), Qualitative research: Theory, method and practice. London: Sage Publications.

Hwang, H., \& Powell, W. W. (2009). The rationalization of charity: The influences of professionalism in the nonprofit sector. Administrative Science Quarterly, 54, 268-298.

Jansson, N. (2013). Organizational change as practice: A critical analysis. Journal of Organizational Change Management, 26(6), 1003-1019.

Jarzabkowski, P. (2008). Shaping strategy as a structuration process. Academy of Management Journal, 51(4), 621-650.

Langley, A. N. N. (1999). Strategies for theorizing from process data. The Academy of Management Review, 24(4), 691-710.

Langley, A. (2011). Studying processes in and around organizations. In D. A. Buchanan \& A. Bryman (Eds.), Organizational research methods (pp. 409-429). Los Angeles: SAGE Publications.

Leiter, J. (2013). An industry fields approach to isomorphism involving Australian nonprofit organizations. Voluntas, 24(4), 1037-1070.

Lipsky, M. (1980). Street-level bureaucracy: Dilemmas of the individual in public services. New York, NY: Russell Sage Foundation.

Lipsky, M., \& Smith, S. R. (1989). Nonprofit organizations, government, and the welfare state. Political Science Quarterly, 104, 625-648.

Macmillan, R. (2011) Seeing things differently? The promise of qualitative longitudinal research on the third sector. Working Paper No. 56. Third Sector Research Centre, Birmingham University.

Oliver, C. (1991). Strategic responses to institutional processes. Academy of Management Review, 16(1), 145-179. https://doi. org/10.5465/AMR.1991.4279002.

Pache, A. C., \& Santos, F. (2010). When worlds collide: The internal dynamics of organizational responses to conflicting institutional demands. Academy of Management Review, 35(3), 455-476.
Pettigrew, A. M., Woodman, R. W., \& Gaivieron, K. I. M. S. (2001). Studying organizational change and development: Challenges for future research. Academy of Management Journal, 44(4), $697-714$

Ponterotto, J. G. (2006). Brief note on the origins, evolution and meaning of the qualitative research concept thick description. The Qualitative Report, 11(3), 538-549.

Ragin, C. C. (1992). Introduction: Cases of "What is a case?". In C. C. Ragin \& H. Becker (Eds.), What is a case? Exploring the foundations of social inquiry (pp. 1-18). New York: Cambridge University Press.

Safeguarding of Vulnerable Groups Act. (2006). The National Archives on behalf of HM Government, UK. http://www. legislation.gov.uk.

Sturdy, A., \& Grey, C. (2003). Beneath and beyond organizational change management: Exploring alternatives. Organization, 10(4), 651-662.

Taylor, R., Arvidson, M., Macmillan, R., Soteri-Proctor, A., \& Teasdale, S. (2014). What's in it for us? Consent, access, and the meaning of research in a qualitative longitudinal study. In L. Camfield (Ed.), Methodological challenges and new approaches to research in international development (pp. 38-58). New York: Palgrave Macmillan.

Townley, B. (2002). The role of competing rationalities in institutional change. Academy of Management Journal, 45(1), $163-179$.

Tsoukas, H. (2011). Craving for generality and small-N studies. In D. Buchanan \& A. Bryman (Eds.), The Sage handbook of organizational research methods (pp. 285-301). London: SAGE Publications.

Tsoukas, H., \& Chia, R. (2002). On organizational becoming: Rethinking organizational on organizational becoming: Rethinking organizational change. Organization Science, 13(5), $567-582$.

Turco, C. (2012). Difficult decoupling: Employee resistance to the commercialization of personal settings. American Journal of Sociology, 118(2), 380-419.

Van de Ven, A. H., \& Huber, G. P. (1990). Longitudinal field research methods for studying processes of organizational change. Organization Science, 1(3), 213-219.

Van de Ven, A. H., \& Poole, M. S. (2005). Alternative approaches for studying organizational change. Organization Studies, 26(9), 1377-1404.

Verbruggen, S., Christiaens, J., \& Milis, K. (2011). Can resource dependence and coercive isomorphism explain nonprofit organizations' compliance with reporting standards? Nonprofit and Voluntary Sector Quarterly, 40(1), 5-32.

Weick, K. E., \& Quinn, R. E. (1999). Organizational change and development. Annual Review of Psychology, 50, 361-386.

Wetzel, R., \& Van Gorp, L. (2014). Eighteen shades of grey? Journal of Organizational Change Management, 27(1), 115-146. 